\title{
Global prevalence of osteoporosis among the world older adults: a comprehensive systematic review and meta-analysis
}

\author{
Nader Salari ${ }^{1}$, Niloofar Darvishi², Yalda Bartina ${ }^{3}$, Mojdeh Larti ${ }^{2}$, Aliakbar Kiaei ${ }^{4}$, Mahvan Hemmati ${ }^{2}$, \\ Shamarina Shohaimi ${ }^{5}$ and Masoud Mohammadi ${ }^{*}$ (D)
}

\begin{abstract}
Background: Osteoporosis is one of the most common bone system diseases that is associated with an increased risk of bone fractures and causes many complications for patients. With age, the prevalence of this disease increases so that it has become a serious problem among the elders. In this study, the prevalence of osteoporosis among elders around the world is examined to gain an understanding of its prevalence pattern.

Methods: In this systematic review and meta-analysis, articles that have focused on prevalence of osteoporosis in the world's elders were searched with these key words, such as Prevalence, Osteoporosis, Elders, Older adult in the Science Direct, Embase, Scopus, PubMed, Web of Science (WoS) databases and Google Scholar search engine, and extracted without time limit until March 2020 and transferred to information management software (EndNote). Then, duplicate studies were eliminated and the remaining studies were evaluated in terms of screening, competence and qualitative evaluation based on inclusion and exclusion criteria. Data analysis was performed with Comprehensive Meta-Analysis software (Version 2) and Begg and Mazumdar test was used to check the publication bias and $\mathrm{I}^{2}$ test was used to check the heterogeneity.
\end{abstract}

Results: In a review of 40 studies (31 studies related to Asia, 5 studies related to Europe and 4 studies related to America) with a total sample size of 79,127 people, the prevalence of osteoporosis in the elders of the world; $21.7 \%$ (95\% confidence interval: 18.8-25\%) and the overall prevalence of osteoporosis in older men and women in the world, 35.3\% (95\% confidence interval: 27.9-43.4\%), 12.5\% (95\% confidence interval: 9.3-16.7\%) was reported. Also, the highest prevalence of osteoporosis in the elders was reported in Asia with; 24.3\% (95\% confidence interval: 20.9-28.1\%)

Conclusion: The results of the present study showed that the prevalence of osteoporosis in the elders and especially elders' women is very high. Osteoporosis was once thought to be an inseparable part of elders'lives. Nowadays, Osteoporosis can be prevented due to significant scientific advances in its causes, diagnosis, and treatment. Regarding the growing number of elderly people in the world, it is necessary for health policy-makers to think of measures to prevent and treat osteoporosis among the elders.

Keywords: Prevalence, Osteoporosis, Elders, Systematic review, Meta-analysis

*Correspondence: Masoud.mohammadi1989@yahoo.com

${ }^{6}$ Department of Nursing, School of Nursing and Midwifery, Kermanshah University of Medical Sciences, Kermanshah, Iran

Full list of author information is available at the end of the article

\section{Background}

Osteoporosis is characterized by a decrease in bone mass and destruction. According to an internationally agreed definition, people with $\mathrm{BMD} \leq-2.5$ have a standard original author(s) and the source, provide a link to the Creative Commons licence, and indicate if changes were made. The images or other third party material in this article are included in the article's Creative Commons licence, unless indicated otherwise in a credit line to the material. If material is not included in the article's Creative Commons licence and your intended use is not permitted by statutory regulation or exceeds the permitted use, you will need to obtain permission directly from the copyright holder. To view a copy of this licence, visit http://creativecommons.org/licenses/by/4.0/. The Creative Commons Public Domain Dedication waiver (http://creativeco mmons.org/publicdomain/zero/1.0/) applies to the data made available in this article, unless otherwise stated in a credit line to the data. 
deviation less than the average healthy young population with osteoporosis [1]. In the last century, the average life expectancy of people has increased because of the increase in safety, life expectancy, and observance of health principles. As a result, the elderly population has expanded significantly [2]. According to the WHO, the elderly population will reach 12 billion by 2025 [3]. Aging is associated with chronic diseases, disabilities and cognitive decline [4]. Hypertension, sleep disorders, malnutrition, obesity, and osteoporosis and an increased risk of falls are other problems associated with aging $[2,5-8]$. Therefore, the costs of treatment and social support are increasing day by day [4]. Osteoporosis is the most common metabolic disease, especially in the elders [9-11]. The prevalence of osteoporosis among the elders in 2020 in Spain and China was reported to be $39.3 \%$ and $39.4 \%$, respectively $[12,13]$. This amount was reported $49 \%$ in Nepal in 2019, 11\% in Taiwan and 7.9\% in Iran $[9,14,15]$. Female gender, age, marital status, history of peptic ulcer and fracture, and Osteoarthropathy are associated with osteoporosis in the elders [10].

Osteoporosis and osteoporotic fractures directly and indirectly impose a high cost on the global economy [16]. The annual cost of osteoporosis to the US health care system is at least \$ 5-10 billion [17]. Osteoporosis increases the risk of fractures. Fractures can lead to decreased quality of life, hospitalization, disability and increased mortality $[18,19]$. Osteoporotic fractures, especially vertebral fractures, can be associated with chronic debilitating pain. One in five patients with a pelvic fracture dies within a year [20]. Bone fractures make daily activities difficult. Only one-third of patients with fractures return to their previous level of function, and one-third of these patients require hospitalization in nursing homes [20].

In addition to fractures, osteoporosis can increase hospitalization rates due to associated secondary complications [21]. There are more than 8.9 million osteoporotic fractures worldwide. In other words, an osteoporotic fracture occurs every three seconds [22]. In the USA, about 1.5 million fractures occur due to osteoporosis each year [17]. It is estimated that one in three women and one in five men over the age of 50 suffer osteoporotic fractures [20]. More than one-third of adult women suffer from one or more osteoporotic fractures [23]. Due to the rapid increase in the average age of the population, an increase in the number of people with osteoporosis and, consequently, an increase in the number of fractures due to osteoporosis can be predicted [16]. The elderly population suffers more than others from the complications of osteoporosis [4]. The prevalence of osteoporosis among the elders was reported $36.1 \%$ in India. The figures were reported 1.6\%, 19\%, and $49 \%$ in Canada, Denmark, and Nepal, respectively $[1,14,24,25]$. As can be seen, the prevalence of osteoporosis in the elders varies greatly in different countries and there is no accurate idea of the overall prevalence of osteoporosis in the world. Accordingly, the aim of this study was to investigate the prevalence of osteoporosis in the world's elders through systematic review and meta-analysis.

\section{Methods}

This study was conducted in accordance with the criteria of the Preferred Reporting Items for Systematic Reviews and Meta-Analyses (PRISMA) [26]. Based on which, systematic search of databases, organization of documents for review, selection of studies in accordance with the criteria defined by the authors, information extraction, analysis and finally the presentation of the final report were implemented.

\section{Search strategy}

Systematic search of articles was performed in Google Scholar, Science Direct, Scopus, Web of science (WoS), PubMed, SID, Magiran databases. The keywords used for the search in this study were selected based on published preliminary studies and also Medical Subject Headings (MESH Terms) in the reviewed database. Also, a detailed study of the questions in this study and the keywords were selected according to PECO criteria [27].

PECO criteria included Participants: In this study, men and women older adults [28], Exposure: among all the elders, the elders with osteoporosis were examined, Comparison: Osteoporosis was considered in the elders of different communities, Outcomes: The overall prevalence of osteoporosis was reported by gender and continent. The selected keywords in this study were in English and their Persian equivalents were used in Persian databases. These keywords included Prevalence, Osteoporosis, Elders, Older adult. The Boolean search method was also used to combine the keywords. The search was conducted in various databases without time limit and until March 2020. References to past related studies and the Google Scholar search engine were also further explored to find relevant empirical studies.

\section{Inclusion and exclusion criteria}

Inclusion criteria included cross-sectional studies that focused on the prevalence of osteoporosis in the elders, studies that have the full text available and the information in the present study, and exclusion criteria included observational studies such as control case and cohort studies, case report studies, case series, review studies, intervention and clinical trial studies. 


\section{Selection of studies}

After collecting the studies researched in EndNote software, the studies were started by the authors. Evaluations in this study were performed independently and blinded. In order to keep the information of the authors of the article anonymous, the journal title and the author name(s) were removed from the review list of articles, and then, the full text of the article was provided to reviewers. Initially, two researchers (ND and $\mathrm{ML}$ ) reviewed the titles and abstracts of articles (according to inclusion criteria). In case of disagreement among the researchers regarding each of the articles, the third party (MM) reviewed and provided the final opinion regarding that study. Then, the full text of the studies confirmed in the initial evaluation was reviewed by the same researchers in terms of criteria defined according to the PECO criterion.

\section{Quality evaluation}

The quality of confirmatory studies in the previous stages was measured by the methodological quality assessment tool of observational studies. The STROBE checklist [29] was used in this study. This checklist examines various aspects of writing a study, including title, problem statement, study objectives, study type, statistical population, sampling method, determining the appropriate sample size, defining variables and procedures, study data collection tools, statistical analysis methods and findings. Since the surveys in this checklist are done using 32 different fields. A score was assigned in the range of 0-32 to the studies. Due to the fact that in this systematic review, studies with good or average quality were included in the analysis, articles that received a score of 16 and above were selected by the authors, and studies with a score of less than 16 were considered to be of poor quality and excluded.

\section{Data extraction and analysis}

Data were extracted through pre-designed forms. Various criteria such as demographic information (first author, year of publication, country, continent, study population, age mean) and the number of people with osteoporosis in general and by population were extracted and entered into the relevant forms, and Comprehensive Meta-Analysis software (Version 2) was used to analyze the data. Due to the high number of studies reviewed in this systematic review, the Begg and Mazumdar test at a significance level of 0.1 and the corresponding Funnel plot were used to investigate the publication bias. The $I^{2}(\%)$ test was used to assess the heterogeneity of the selected research works. Finally, using meta-regression test, the relationship between the prevalence of osteoporosis in the elders with the sample size, year of publication and age of participants in the study and analysis of meta-analysis by continent and sex was also investigated.

\section{Results}

In this systematic review and meta-analysis, studies on the prevalence of osteoporosis in the world without time limit until March 2020 and according to PRISMA guidelines were systematically reviewed. Based on the initial search in the database, 3144 possible related articles were identified and transferred to the information management software (EndNote). Out of a total of 3144 identified studies, 132 were duplicate and were excluded. In the screening phase of the remaining 3012 studies, 2736 articles were excluded through the study of titles and abstracts based on inclusion and exclusion criteria. In the competency evaluation stage, out of the remaining 276 studies, 232 articles were excluded by reading the full text of the article based on inclusion and exclusion criteria due to irrelevance. In the qualitative evaluation stage, by studying the full text of the article and based on the score obtained from the STROBE checklist, out of the remaining 44 studies, 4 articles that had poor methodological quality were excluded. Finally, 40 studies entered the final analysis (Fig. 1).

The results of a systematic review of the studies in Tables 1 and 2 were reported based on the osteoporosis screening indices as well as the country in which the study was conducted. The lowest and highest sample sizes were related to the studies of Bakir et al. (2018) $(n=38)$ [30] and Lau et al. $(2015)(n=12,401)$ [31].

Based on the test results $\left(I^{2}: 99.07\right)$ and due to the heterogeneity of selected studies, a random effects model was used to combine the studies and share the prevalence estimate. The reason for heterogeneity between studies can be due to differences in sample size, sampling error, year of study or place of study. The probability of publication bias in results of the prevalence of osteoporosis in the elders in the world by funnel diagram and Begg and Mazumdar test at a significance level of 0.1 showed no publication bias of the prevalence in the present study $(P=0.278)$ (Fig. 2). Due to the high sample size studied in the study (79,127 elderly), in order to evaluate the results of publication bias, the Begg and Mazumdar test was used at a significance level of 0.1 . However, the report of the results based on the Egger's test, which is more consistent with the funnel plot, was reported at the level of 0.05 , which again, the publication bias was not significant (0.129).

In an investigation of 40 studies (31 studies in Asia, 5 studies in Europe, 4 studies in the Americas) with a total sample size of 79,127 people in the age range between 50 and 85 years, the prevalence of osteoporosis in the world 


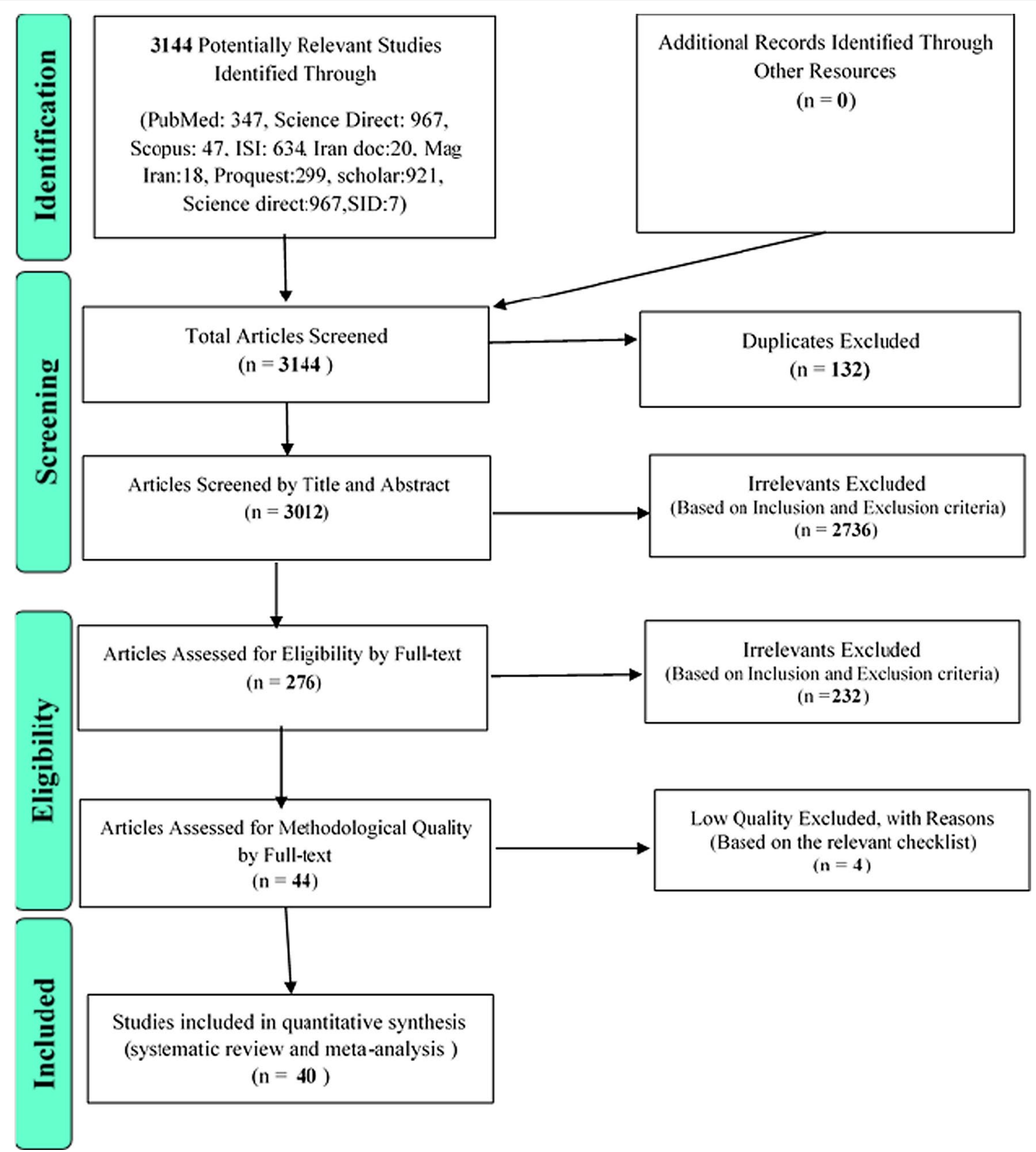

Fig. 1 The flowchart on the stages of including the studies in the systematic review and meta-analysis (PRISMA 2009)

elders; $21.7 \%$ (95\% confidence interval: $18.8-25 \%$ ) was obtained. The shape of Forrest Plot 3 reports the overall prevalence in the investigated studies, which shows the midpoint of each segment of the prevalence in each study, and the rhombus shape shows the prevalence in the population for the entire study (Fig. 3).

The results reported by the prevalence of osteoporosis in the elders by sex in Table 2 show that the highest and lowest prevalence of osteoporosis reported in elders women studied in China and in the 2017 Yixuan Ma study [57] with 69.2\% (95\% confidence interval: 65.5.8-72.6\%) and in Malaysia and in the Kok-Yong Chin study [41], in 2016 with 7.5\% (95\% confidence interval: $5.2-10.7 \%$ ), and the highest and lowest prevalence of osteoporosis reported in elders men studied in China and in the Yixuan Ma study [57] in 2017 with $52.1 \%$ (95\% confidence interval: $47.8-56.4 \%$ ) and in Japan and in the Daisuke asaoka study [34], it was 
Table 1 Data on studies included in the meta-analysis

\begin{tabular}{|c|c|c|c|c|c|c|}
\hline Number & First author & Year & Region & Age range & Total sample size & $\begin{array}{l}\text { Total } \\
\text { prevalence of } \\
\text { osteoporosis }\end{array}$ \\
\hline 1 & Ana Carolina Veiga Silva [32] & 2015 & Brazil & $\geq 66$ & 468 & 25.4 \\
\hline 2 & Antonio Juan [12] & 2020 & Spain & 65 & 731 & 39.3 \\
\hline 3 & Anuk Kruavit [33] & 2012 & Thailand & 75.2 & 93 & 47.3 \\
\hline 4 & B.R. Nielsen [1] & 2020 & Denmark & 75 & 529 & 19 \\
\hline 5 & $\begin{array}{l}\text { Bi Bi Fatemeh Nobakht Motlagh } \\
\text { Ghochani [34] }\end{array}$ & 2013 & Iran & 56.4 & 430 & 34.1 \\
\hline 6 & Carlos Mautalen [35] & 2016 & Argentina & $\geq 50$ & 5448 & 18.7 \\
\hline 7 & Chi-Hua Ko [15] & 2018 & Taiwan & - & 3144 & 11 \\
\hline 8 & Daisuke Asaoka [36] & 2015 & Japan & 63.2 & 255 & 16.8 \\
\hline 9 & Dong-Hyeon Lee [37] & 2013 & Korea & 55 & 1727 & 23.9 \\
\hline 10 & Edith Ming Chu Lau [31] & 2015 & China & $50-89$ & 12,401 & 22.5 \\
\hline 11 & Esad Alibasic [38] & 2013 & Bosnia And Herzegovina & 70 & 711 & 8.8 \\
\hline 12 & Eun Jung Park [39] & 2014 & Korea & $\geq 60$ & 4538 & 33.8 \\
\hline 13 & Khurshid A. Bhat [40] & 2018 & India & 68 & 241 & 19.9 \\
\hline 14 & Kok-Yong Chin [41] & 2016 & Malaysia & 63.38 & 645 & 10 \\
\hline 15 & Kyae Hyung Kim [42] & 2012 & Korea & $\geq 50$ & 2870 & 39 \\
\hline 16 & Kyung-Shik Lee [43] & 2014 & Korea & $\geq 60$ & 6864 & 32.9 \\
\hline 17 & Limin Tian [44] & 2017 & China & $\geq 60$ & 5160 & 10.8 \\
\hline 18 & M Maddah [45] & 2011 & Iran & $50-75$ & 706 & 15.5 \\
\hline 19 & Marie-Therese Puth [46] & 2018 & Germany & $\geq 65$ & 4418 & 12.2 \\
\hline 20 & Mohamed Adel Bakir [30] & 2018 & Syria & 62 & 38 & 13.1 \\
\hline 21 & Narendra Kumar Chaudhary [14] & 2019 & Nepal & $\geq 60$ & 102 & 49 \\
\hline 22 & Neeraj Kumar Agrawal [47] & 2013 & India & $62.61(\geq 50)$ & 200 & 8.5 \\
\hline 23 & P. Modagan [25] & 2018 & India & $\geq 60$ & 304 & 36.1 \\
\hline 24 & Paolo Bucciarelli [48] & 2010 & Italy & $65.1(38-87)$ & 446 & 13.2 \\
\hline 25 & Parvin Cheraghi [9] & 2018 & Iran & 74.9 & 1779 & 7.9 \\
\hline 26 & Po-Han Chen [49] & 2017 & Taiwan & 66.7 & 941 & 16.7 \\
\hline 27 & Qian Zhang [13] & 2020 & China & 81.2 & 565 & 39.4 \\
\hline 28 & Qiang Zeng [11] & 2019 & China & $\geq 65$ & 8479 & 30.2 \\
\hline 29 & Renu Gupta [50] & 2012 & Kuwait & $\geq 60$ & 1010 & 28.9 \\
\hline 30 & Robert Ferrari [24] & 2015 & Canada & 70.5 & 557 & 1.6 \\
\hline 31 & Rongtao Cui [51] & 2016 & China & $>65$ & 1394 & 9 \\
\hline 32 & Sabrina E Noel [52] & 2018 & Puerto Rico & $\geq 60$ & 438 & 12.1 \\
\hline 33 & Sahana Shetty [53] & 2014 & India & 58 & 252 & 19.8 \\
\hline 34 & Sarath Lekamwasam [54] & 2009 & Sri Lanka & $\geq 60$ & 337 & 11.5 \\
\hline 35 & Xiao-Guang Cheng [55] & 2007 & China & $\geq 50$ & 5083 & 31 \\
\hline 36 & Yin-Fan Chang [56] & 2016 & Taiwan & 74 & 368 & 35.1 \\
\hline 37 & Yixuan Ma [57] & 2018 & China & 66.9 & 1168 & 61.6 \\
\hline 38 & Yong Jun Choi [58] & 2012 & Korea & $\geq 60$ & 3140 & 32.4 \\
\hline 39 & Zahra Pourhashem [59] & 2012 & Iran & 68.39 & 193 & 32.1 \\
\hline 40 & Zhifeng Sheng [60] & 2011 & China & $62(50-82)$ & 954 & 39.4 \\
\hline
\end{tabular}

obtained in 2015 with 5\% (95\% confidence interval: 2.3-10.7\%) (Table 2).

The results of the meta-analysis reported in Fig. 4 report that the overall prevalence of osteoporosis in the elderly women of the world and the $95 \%$ confidence interval based on the random effects model was $35.3 \%$ (95\% confidence interval: 27.9-43.4\%). Heterogeneity of studies $\left(I^{2}: 99.2\right)$ and random effects model was used to evaluate the results. Also, the results of publication bias based on Begg and Mazumdar test at a significance level 
Table 2 Data on studies included in meta-analysis by gender

\begin{tabular}{|c|c|c|c|c|c|c|c|}
\hline Number & First author & Year & $\begin{array}{l}\text { Females' } \\
\text { number }\end{array}$ & Males' number & $\begin{array}{l}\text { Total prevalence } \\
\text { of osteoporosis }\end{array}$ & $\begin{array}{l}\text { Prevalence of } \\
\text { osteoporosis in } \\
\text { women }\end{array}$ & $\begin{array}{l}\text { Prevalence of } \\
\text { osteoporosis in } \\
\text { men }\end{array}$ \\
\hline 1 & B.R. Nielsen [1] & 2020 & 297 & 323 & 101 & 22.2 & 10.8 \\
\hline 2 & Daisuke asaoka [36] & 2015 & 135 & 120 & 43 & 27.4 & 5 \\
\hline 3 & Dong-Hyeon Lee Bakir [37] & 2013 & 813 & 914 & 414 & 37.5 & 11.9 \\
\hline 4 & Eun Jung Park [39] & 2014 & 2442 & 2096 & 1538 & 52.9 & 11.8 \\
\hline 5 & Kok-Yong Chin [41] & 2016 & 362 & 283 & 65 & 7.5 & 13.4 \\
\hline 6 & Kyung-Shik Lee [43] & 2014 & 3528 & 3336 & 2263 & 45 & 20.3 \\
\hline 7 & Limin Tian [44] & 2017 & 1955 & 3205 & 560 & 15.4 & 8.1 \\
\hline 8 & P. Modagan [25] & 2018 & 152 & 152 & 110 & 50.7 & 21.7 \\
\hline 9 & Qiang Zeng [11] & 2019 & 4597 & 3882 & 2569 & 45.9 & 11.8 \\
\hline 10 & Rongtao Cui [51] & 2016 & 908 & 486 & 126 & 13 & 1.6 \\
\hline 11 & Sabrina E Noel [52] & 2018 & 315 & 123 & 53 & 14 & 7.3 \\
\hline 12 & Y. Lim [61] & 2017 & 2775 & 1760 & 2050 & 61.9 & 18.8 \\
\hline 13 & Yixuan Ma [57] & 2017 & 652 & 516 & 720 & 69.2 & 52.1 \\
\hline 14 & Yong Jun Choi [58] & 2012 & 1816 & 1324 & 1018 & 52.6 & 11.6 \\
\hline 15 & Zahra Pourhashem [59] & 2012 & 88 & 105 & 62 & 55.7 & 12.4 \\
\hline
\end{tabular}

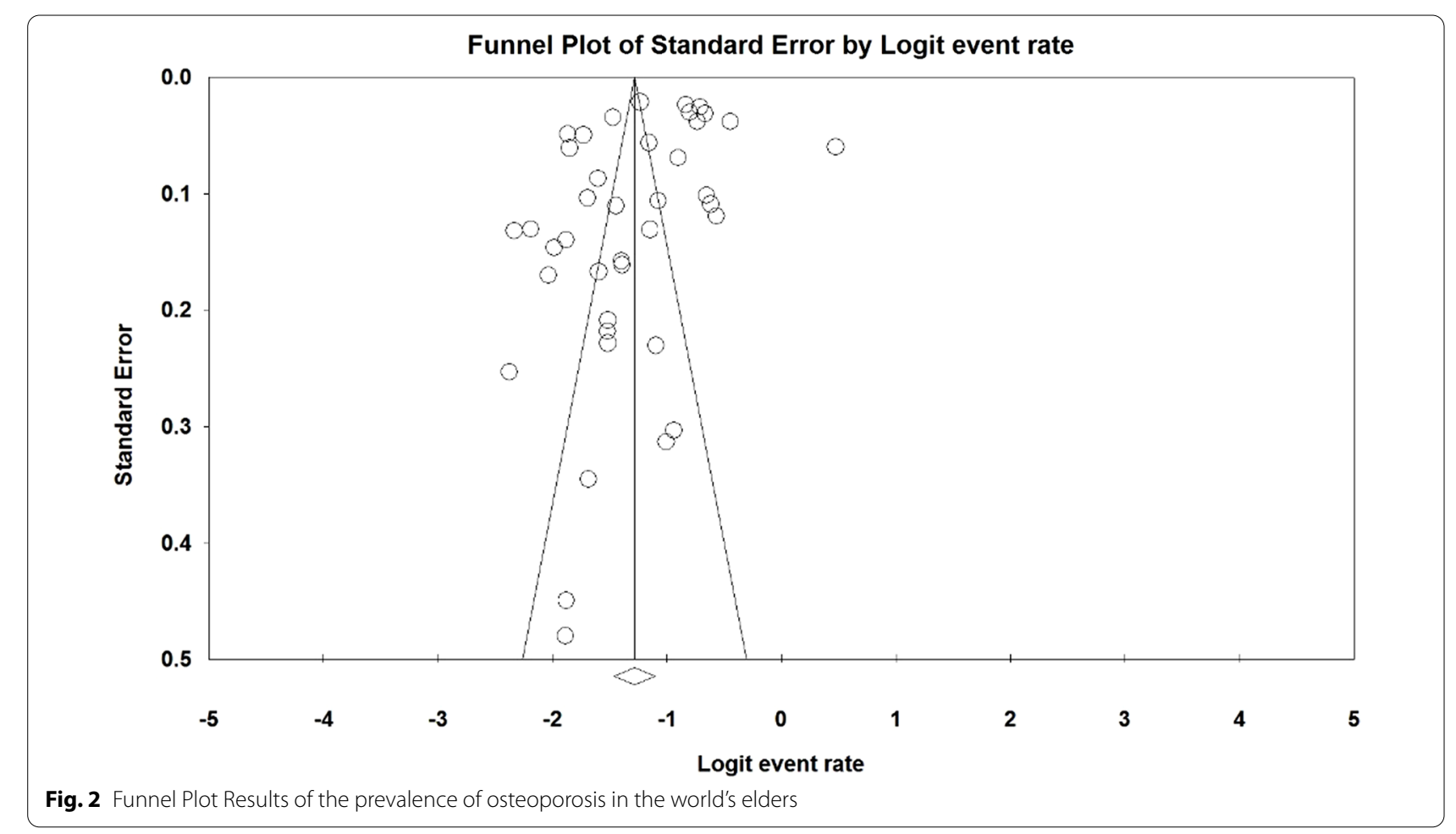

of 0.1 showed no publication bias in the present study $(P=0.276)$ (Fig. 4).

Also, the overall prevalence of osteoporosis in the elder's men of the world and the 95\% confidence interval based on the random effect model was reported to be $12.5 \%$ (95\% confidence interval: $9.3-16.7 \%)$, heterogeneity of studies $\left(I^{2}: 98.1\right)$ and random effect model was used to evaluate the results. Also, the results of publication bias based on Begg and Mazumdar test at a significance level of 0.1 showed no publication bias in the present study $(P=1.000)$ (Fig. 5). 
Meta Analysis

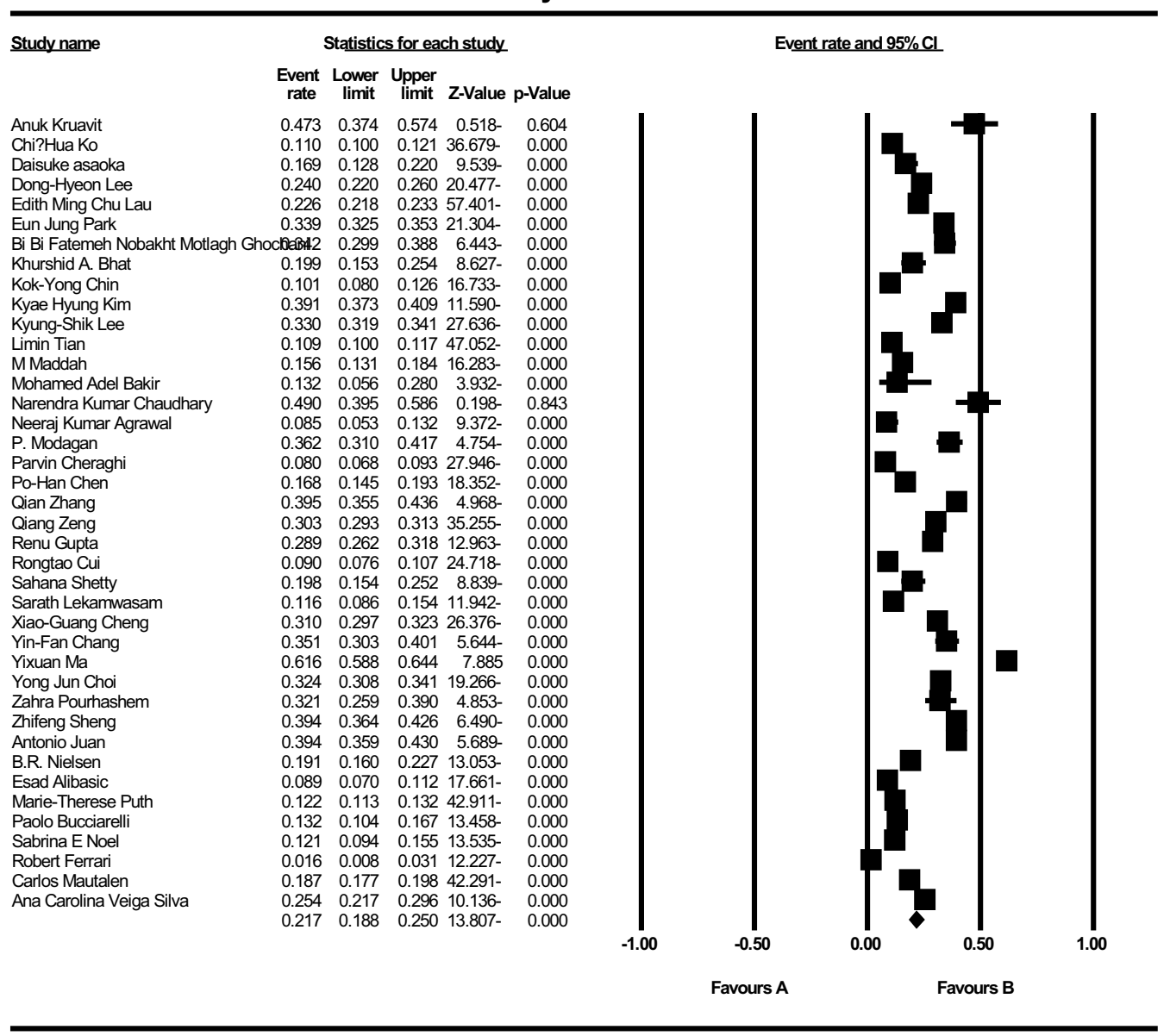

Meta Analysis

Fig. 3 Prevalence of osteoporosis in the world's elders and 95\% confidence interval based on random effect model

\section{Meta-regression test}

In order to investigate the effects of potential factors in the heterogeneity of the prevalence of osteoporosis in the elders around the world, meta-regression was used on three factors: sample size, year of study and age of study participants (Figs. 6, 7, 8). According to Fig. 6, the prevalence of osteoporosis in the world elders decreases with increasing sample size, which is statistically significant $(P<0.05)$. This difference was also statistically significant $(P<0.05)$, but the results reported in Fig. 8 show that the prevalence of osteoporosis in the elders increases with age, which was also statistically significant $(P<0.05)$.

\section{Subgroup analysis}

Table 3 reports the prevalence of osteoporosis in the elders of the world by different continents; these changes are reported in Asia, Europe, and the Americas, according to the results of this table, the highest prevalence of osteoporosis in the elders was Asia with $24.3 \%$ (95\% confidence interval: 20.9-28.1\%) (Table 3).

\section{Discussion}

In a systematic review of 40 studies, the results of the meta-analysis of the present study report that the prevalence of osteoporosis in the world's elders was obtained $21.7 \%$. Based on the results of subgroup analysis, the prevalence of osteoporosis in Asia, Europe, and the USA was $24.3 \%, 16.7 \%$, and $11.5 \%$, respectively, with the highest prevalence in Asia.

Risk of osteoporosis in older people who need help, or have a functional defect is more than older people with favorable self-care activities [13]. In China in 2015, the prevalence of osteoporosis in people aged 50 and older was reported to be $16.96 \%$, more than double the prevalence detected in 2006 [62]. 


\section{Meta Analysis}

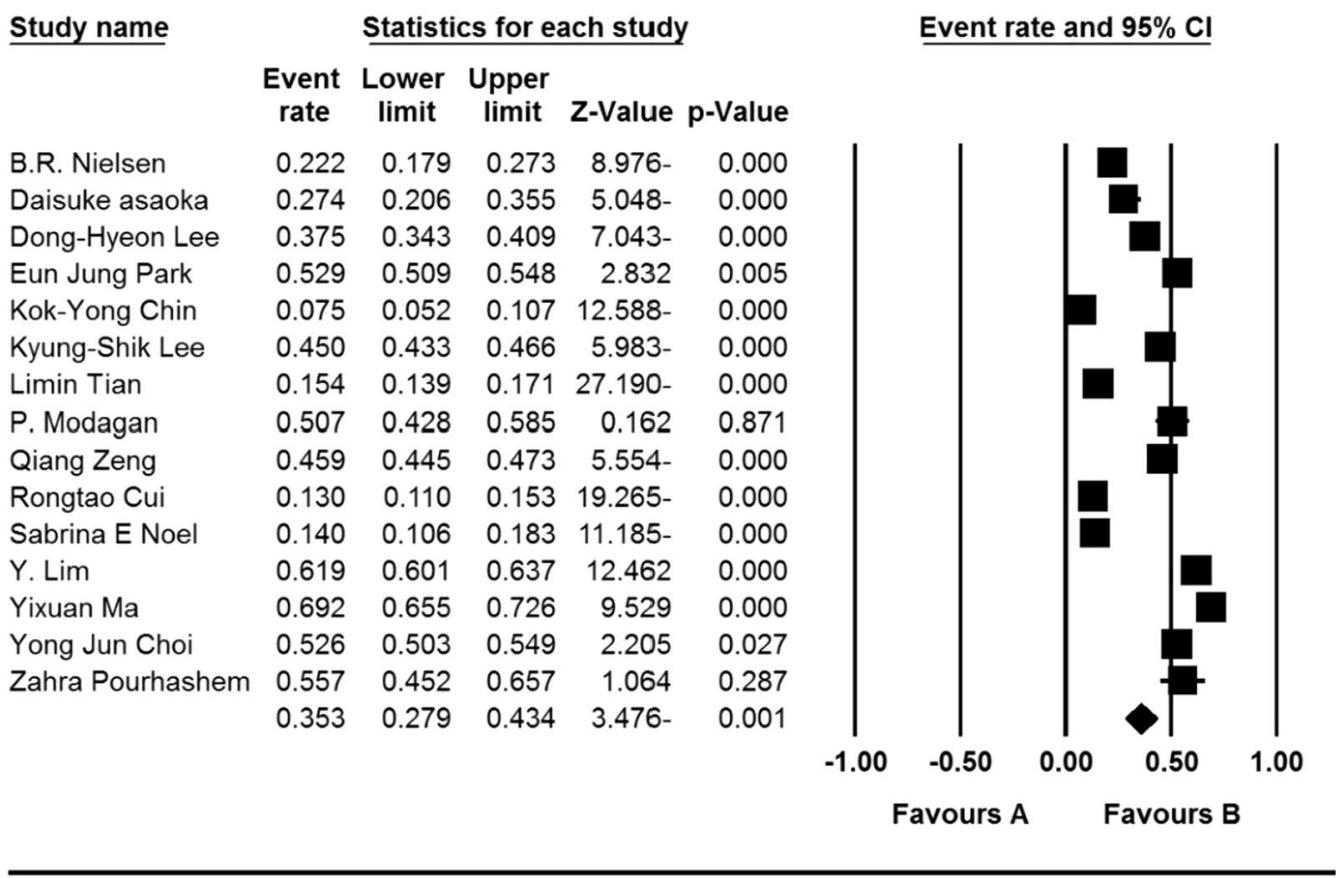

Meta Analysis

Fig. 4 Prevalence of osteoporosis among elderly women worldwide and 95\% confidence interval based on random effect model

In the Eastern Mediterranean, the prevalence of osteoporosis was reported $24.4 \%$. The highest prevalence of osteoporosis was related to Saudi Arabia with 32.7\% and the lowest prevalence was related to Kuwait with $15.1 \%$. In Eastern Mediterranean countries, due to increased life expectancy, the prevalence of osteoporosis and its complications is increasing [63]. A case study by Zamani et al. [63], and Irani et al. [21] similarly reported issues such as low vitamin $\mathrm{D}$ and calcium intake, less sun exposure, and heavy smoking (more than 20 cigarettes per day), family history of osteoporosis; among the risk factors for osteoporosis in this area.

Based on the results of the present study, it was reported that the overall prevalence of osteoporosis in the elderly women of the world is $35.3 \%$ and in the elder's men of the world is 12.5 . Osteoporosis is more common in women than men. The results of many other studies were in line with the results of the study $[16,21,62]$. Female gender is an independent risk factor for osteoporosis in the elders. This increase may be related to a decrease in postmenopausal estrogen in women [13]. A history of fractures is the most important risk factor for osteoporosis in men [15]. Men generally have more bone mass and content than women. Also, men reach that high level of bone mass compared to women at older ages [64]. The prevalence of osteoporosis among women over 50 is estimated to be about $49 \%$ [65]. About onetenth of women over the age of 60 , one-fifth of women over the age of 70, two-fifths of women over the age of 80 , and two-thirds of women over the age of 90 worldwide have osteoporosis [22]. Women over the age of 50 are 5 times more likely to develop osteoporosis than the normal population. In the study of $\mathrm{Ma}$ et al., the prevalence of osteoporosis was reported $69.1 \%$ in women and $52.1 \%$ in men [57]. In Nielsen et al. and Zeng et al., the prevalence of osteoporosis in men and women was reported to be $22.2 \%, 10.8 \%, 45.9 \%$ and $11.8 \%$, respectively $[1,11]$.

There is some evidence that men are more likely than women to suffer from osteoporosis complications [16]. Women often get fractures 5-10 years earlier than men. Men are generally less likely to be screened for osteoporosis and less likely to seek treatment for fractures [66]. This difference is not due to diet, level of physical activity and weight, but may be related to differences in bone size between the sexes [66]. The prevalence of osteoporosis increases with age. People with osteoporosis were significantly older [13, 15, 21, 62, 63], had lower body weight, shorter height, and more previous fractures than people without osteoporosis [15]. The highest rate of bone loss occurs after the age of 65 [32]. In women, we will see 


\section{Meta Analysis}

\begin{tabular}{|c|c|c|c|c|c|c|c|c|c|}
\hline \multirow[t]{2}{*}{ Study name } & \multicolumn{5}{|c|}{ Statistics for each study } & \multicolumn{4}{|c|}{ Event rate and $95 \% \mathrm{Cl}$} \\
\hline & $\begin{array}{l}\text { Event } \\
\text { rate }\end{array}$ & $\begin{array}{l}\text { Lower } \\
\text { limit }\end{array}$ & $\begin{array}{c}\text { Upper } \\
\text { limit }\end{array}$ & Z-Value & p-Value & & & & \\
\hline B.R. Nielsen & 0.108 & 0.079 & 0.147 & 11.774 & 0.000 & & & & \\
\hline Daisuke asaoka & 0.050 & 0.023 & 0.107 & 7.030 & 0.000 & & & & \\
\hline Dong-Hyeon Lee & 0.119 & 0.100 & 0.142 & $19.591-$ & 0.000 & & & & \\
\hline Eun Jung Park & 0.118 & 0.105 & 0.132 & 29.714 & 0.000 & & & & \\
\hline Kok-Yong Chin & 0.134 & 0.099 & 0.179 & 10.689 & 0.000 & & & & \\
\hline Kyung-Shik Lee & 0.203 & 0.190 & 0.217 & 31.779 & 0.000 & & & & \\
\hline Limin Tian & 0.081 & 0.072 & 0.091 & 37.515 & 0.000 & & & & \\
\hline P. Modagan & 0.217 & 0.159 & 0.290 & $6.519-$ & 0.000 & & & & \\
\hline Qiang Zeng & 0.118 & 0.108 & 0.129 & $40.421-$ & 0.000 & & & & \\
\hline Rongtao Cui & 0.016 & 0.008 & 0.033 & $11.473-$ & 0.000 & & & & \\
\hline Sabrina E Noel & 0.073 & 0.039 & 0.135 & 7.333- & 0.000 & & & & \\
\hline Y. Lim & 0.188 & 0.170 & 0.207 & $23.977-$ & 0.000 & & & & \\
\hline Yixuan Ma & 0.521 & 0.478 & 0.564 & 0.968 & 0.333 & & & & \\
\hline Yong Jun Choi & 0.116 & 0.099 & 0.134 & 23.675 & 0.000 & & & & \\
\hline \multirow[t]{4}{*}{ Zahra Pourhashem } & 0.124 & 0.073 & 0.202 & 6.604 & 0.000 & & & & \\
\hline & 0.125 & 0.093 & 0.167 & $11.251-$ & 0.000 & & & 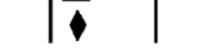 & \\
\hline & & & & & & -1.00 & -0.50 & 0.00 & 1.00 \\
\hline & \multicolumn{9}{|c|}{ Favours A } \\
\hline
\end{tabular}

Meta Analysis

Fig. 5 Prevalence of osteoporosis in the world's elderly men and 95\% confidence interval based on a random effect model

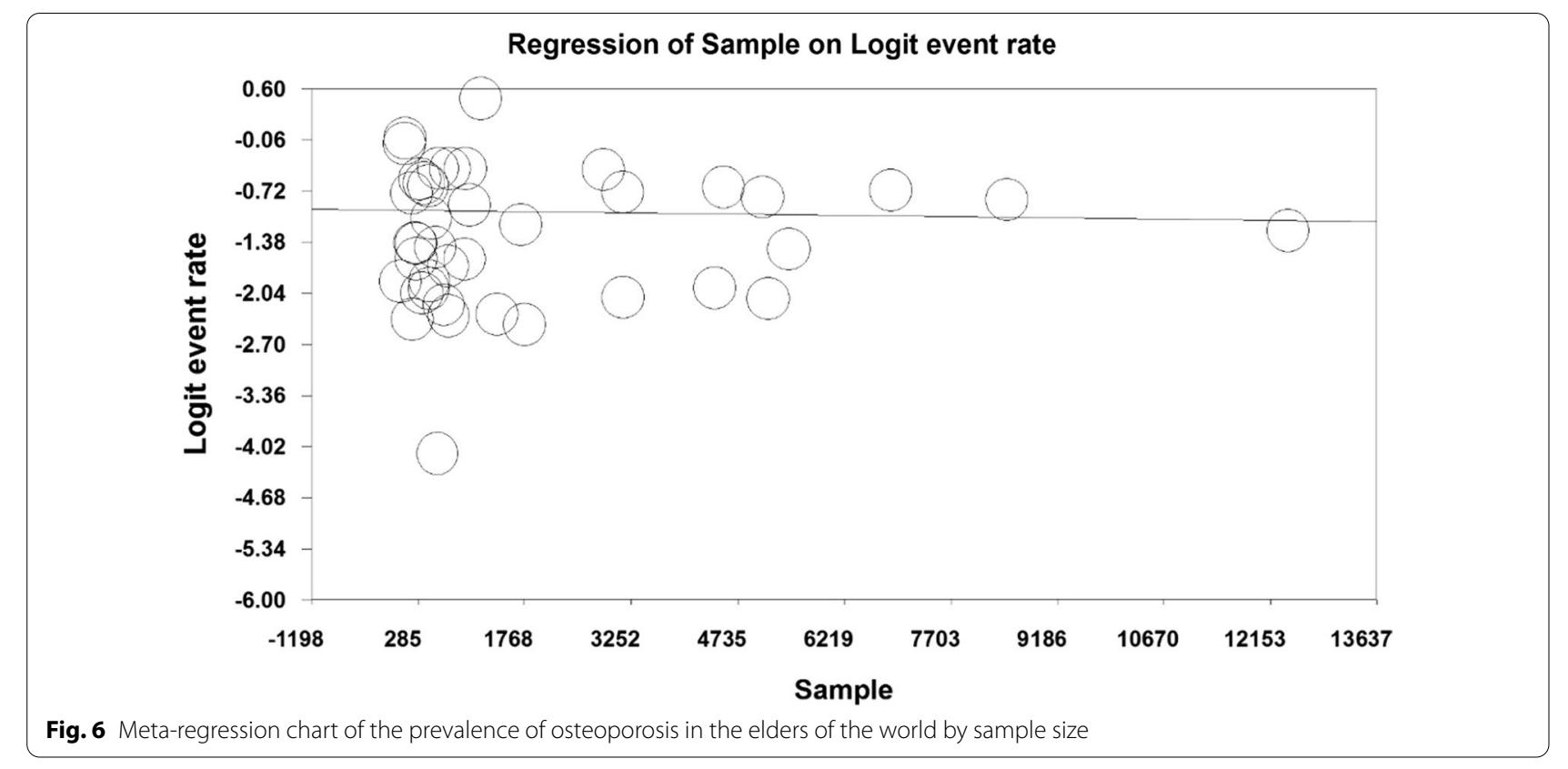

menopause with age. Menopause activates rapid bone resorption in women. It is evident that this problem originates from ovarian insufficiency and can be prevented by estrogen replacement [67]. There is a balance between bone formation and resorption in men and women [32]. The rate of biochemical markers of bone resorption 


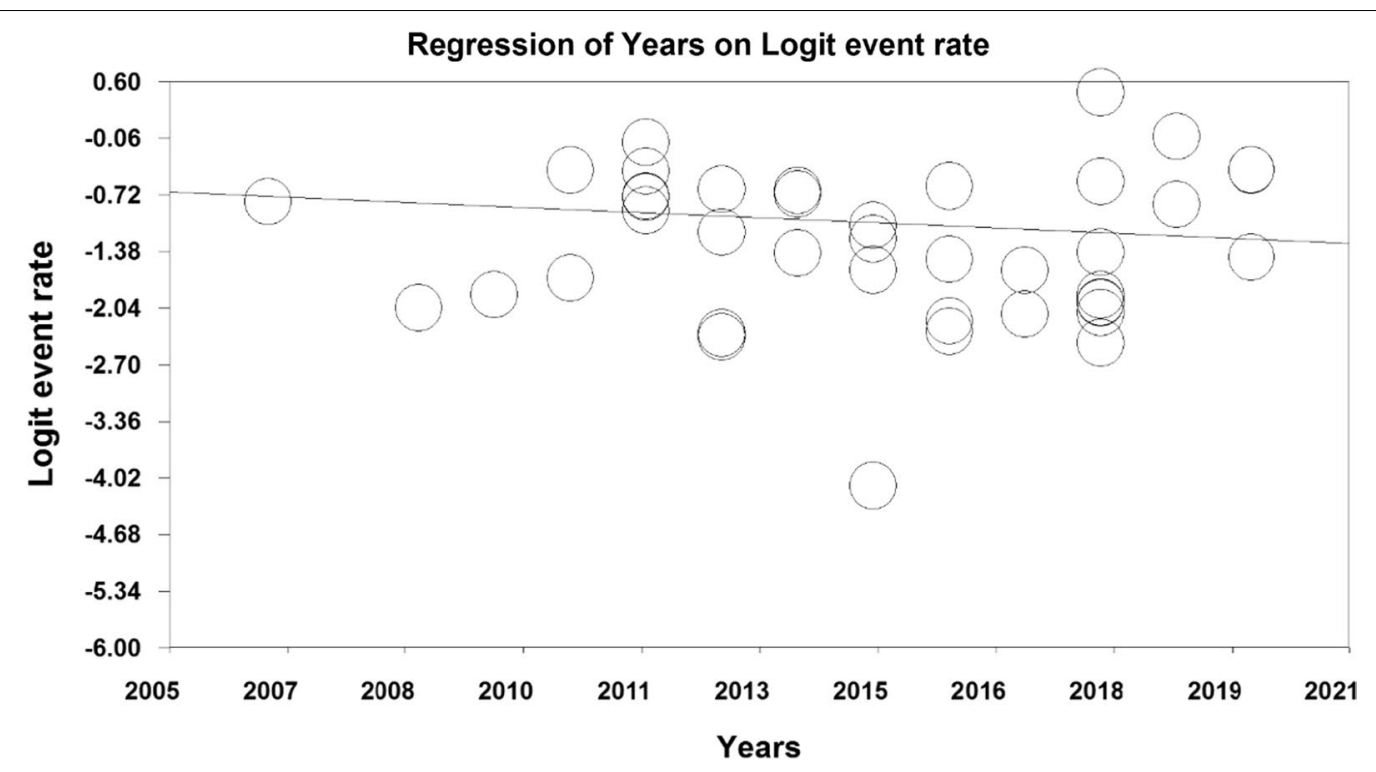

Fig. 7 Meta-regression chart of the prevalence of osteoporosis in the elders of the world by year of study

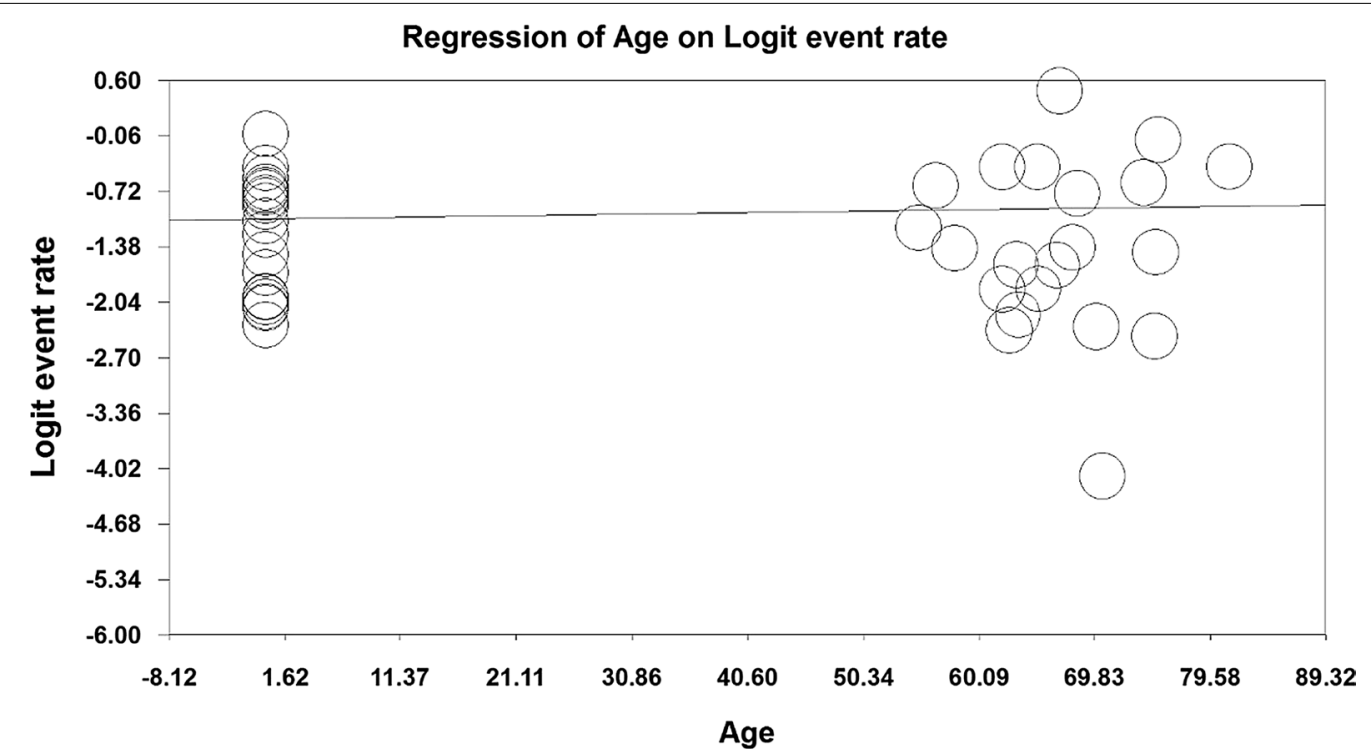

Fig. 8 Meta-regression graph of the prevalence of osteoporosis in the elders of the world by age of study participants

Table 3 Prevalence of osteoporosis in the elders of the world by different continents

\begin{tabular}{llllllr}
\hline Continents & $\begin{array}{l}\text { Number of } \\
\text { articles }\end{array}$ & Sample size & $\mathbf{I}^{\mathbf{2}}$ & & \multicolumn{2}{l}{\begin{tabular}{l} 
Publication bias \\
\cline { 5 - 6 }
\end{tabular}} \\
& & & $\begin{array}{l}\text { Begg and } \\
\text { Mazumdar Test }\end{array}$ & Egger's test & Prevalence \% (95\% Cl) \\
\hline Asia & 31 & 65,381 & 99.06 & 0.284 & 0.298 & $24.3(95 \% \mathrm{Cl}: 20.9-28.1)$ \\
Europe & 5 & 6835 & 99.8 & 1.000 & 0.831 & $16.7(95 \% \mathrm{Cl}: 10.1-29)$ \\
America & 4 & 6911 & 96.5 & 0.308 & 0.410 & $11.5(95 \% \mathrm{Cl}: 5.4-19.1)$ \\
\hline
\end{tabular}


during menopause reaches $90 \%$, while the biomarkers of bone formation reach $45 \%$. This imbalance accelerates bone loss [67].

Based on a meta-analysis conducted worldwide and reviewing 86 studies with a sample size of 103,334,579 in the age range of 15 to 105 years, it was reported that the prevalence of osteoporosis in the world is 18.3\% [68], which shows a high prevalence, while age is a high-risk factor for osteoporosis and Vitamin D insufficiency and reduced calcium absorption are common in the elderly $[69,70]$. Osteoporosis is increasing due to increased life expectancy and an aging population [70]. The prevalence of fragility fractures increases with age, and hip fractures are more common in older age [70,71]. In addition, it is very interesting to mention that $33.3 \%$ of women and $16.6 \%$ of men will sustain a hip fracture by their ninth decade, which is one of the most important causes of osteoporosis in old age.

Although, osteoporosis is more common in women, the risk of osteoporosis in men increases with age. Since most men do not experience overt hypogonadism with age, it was thought that the prevalence of osteoporosis in men was not related to sex hormone levels, but the results of several cross-sectional studies showed a positive and significant relationship between BMD and estrogen levels in men. Decreased serum estradiol levels are also associated with decreased bone density in men [67].

As mentioned, osteoporosis is characterized by a decrease in bone mass. Thus, the decrease in bone mass associated with aging increases the prevalence of osteoporosis in both men and women.

\section{Conclusion}

The results of the present study showed that the prevalence of osteoporosis in the elders, and especially elders' women, is very high. Osteoporosis was once thought to be an inseparable part of older people's lives. Osteoporosis can be prevented today due to significant scientific advances in its causes, diagnosis and treatment. Regarding the growing number of elderly people in the world, it is necessary for health policy-makers to think of measures to prevent and treat osteoporosis among the elders.

\begin{abstract}
Abbreviations
WHO: World Health Organization; WoS: Web of Science; STROBE: Strengthening the reporting of observational studies in epidemiology; PRISMA: Preferred Reporting Items for Systematic Reviews and Meta-Analysis.
\end{abstract}

\section{Acknowledgements}

By Deputy for Research and Technology, Kermanshah University of Medical Sciences.

\section{Authors' contributions}

NS and ND and ML and MM contributed to the design, MM contributed to statistical analysis, participated in most of the study steps. MM and MH and ND and ML and AAK prepared the manuscript. YB and MM and SHSH assisted in designing the study and helped in the interpretation of the study. All authors have read and approved the content of the manuscript.

Funding

By Deputy for Research and Technology, Kermanshah University of Medical Sciences (IR) (4000302). This deputy has no role in the study process.

\section{Availability of data and materials}

Datasets are available through the corresponding author upon reasonable request.

\section{Declarations}

\section{Ethics approval and consent to participate}

Ethics approval was received from the ethics committee of deputy of research and technology, Kermanshah University of Medical Sciences (IR.KUMS. REC.1400.006).

\section{Consent for publication \\ Not applicable.}

\section{Competing interests}

All authors declare that they have no competing interests.

\section{Author details}

${ }^{1}$ Department of Biostatistics, School of Health, Kermanshah University of Medical Sciences, Kermanshah, Iran. ${ }^{2}$ Student research committee, Kermanshah University of Medical Sciences, Kermanshah, Iran. ${ }^{3}$ Department of Translation Studies, Faculty of Literature, Istanbul University, Istanbul, Turkey. ${ }^{4}$ Department of Computer Engineering, Sharif University of Technology, Tehran, Iran. ${ }^{5}$ Department of Biology, Faculty of Science, University Putra Malaysia, Serdang, Selangor, Malaysia. ${ }^{6}$ Department of Nursing, School of Nursing and Midwifery, Kermanshah University of Medical Sciences, Kermanshah, Iran.

Received: 5 October 2021 Accepted: 1 November 2021

Published online: 13 November 2021

\section{References}

1. Nielsen BR, Andersen HE, Haddock B, Hovind P, Schwarz P, Suetta C. Prevalence of muscle dysfunction concomitant with osteoporosis in a home-dwelling Danish population aged 65-93 years-the Copenhagen Sarcopenia Study. Exp Gerontol. 2020;138:110974.

2. Nabavi SH, Hatami ST, Norouzi F, Gerivani Z, Hatami SE, Monadi Ziarat H, Delbari A. Prevalence of fall and its related factors among older people in bojnurd in 2015. Iran J Ageing. 2016;11(3):466-73.

3. Vaisi-Raygani A, Mohammadi M, Jalali R, Ghobadi A, Salari N. The prevalence of obesity in older adults in Iran: a systematic review and metaanalysis. BMC Geriatr. 2019;19(1):1-9.

4. Schuit A. Physical activity, body composition and healthy ageing. Sci Sports. 2006;21(4):209-13.

5. Aliabadi K. Ghayoor M, llityfaizabadi: Prevalence of malnutrition and factors related to it in the elderly subjects in Khorasan Razavi province, Iran, 2006. Iran J Nutr Sci Food Technol. 2008;2(3):45.

6. Khoddam H, Eshkevarlaji S, Nomali M, Modanloo M, Keshtkar AA. Prevalence of malnutrition among elderly people in Iran: protocol for a systematic review and meta-analysis. JMIR Res Protoc. 2019;8(11):e15334.

7. Oskvig RM: Special problems in the elderly. Chest 1999, 115(5, Supplement):158S-164S.

8. Wilson PW, Kannel WB. Obesity, diabetes, and risk of cardiovascular disease in the elderly. Am J Geriatr Cardiol. 2002;11 (2):119-24.

9. Cheraghi $\mathrm{P}$, Cheraghi Z, Bozorgmehr S. The Prevalence and risk factors of osteoporosis among the elderly in Hamadan province: a cross sectional study. Med J Islam Repub Iran. 2018;32:111.

10. Wang Y, Ding H, Wang X, Wei Z, Feng S. Associated factors for osteoporosis and fracture in Chinese elderly. Med Sci Monit. 2019;25:5580-8.

11. Zeng $Q$, Li N, Wang Q, Feng J, Sun D, Zhang Q, Huang J, Wen Q, Hu R, Wang $\mathrm{L}$, et al. The prevalence of osteoporosis in China, a nationwide, 
multicenter DXA survey. J Bone Miner Res Off J Am Soc Bone Miner Res. 2019;34(10):1789-97.

12. Antonio J, Frontera G, Ana Paula C, Ros I, Narváez J, Marí B, Joan Miquel N. Epidemiology of osteoporosis and its determinants in physically active Majorcan elderly. Mediterr J Rheumatol. 2020;31 (1):42-9.

13. Zhang Q, Cai WW, Wang GH, Shen XJ. Prevalence and contributing factors of osteoporosis in the elderly over 70 years old: an epidemiological study of several community health centers in Shanghai. Ann Palliat Med. 2020;9(2):231-8.

14. Chaudhary NK, Timilsena MN, Dev Ram S, Pranil Man Singh P, Sangroula RK. Association of lifestyle and food consumption with bone mineral density among people aged 50 years and above attending the Hospitals of Kathmandu, Nepal. J Osteoporos. 2019;2019:6.

15. Ko CH, Yu SF, Su FM, Chen JF, Chen YC, Su YJ, Lai HM, Chiu WC, Hsu CY, Cheng TT, et al. High prevalence and correlates of osteoporosis in men aged 50 years and over: a nationwide osteoporosis survey in Taiwan. Int J Rheum Dis. 2018;21(12):2112-8.

16. Cui Z, Meng X, Feng H, Zhuang S, Liu Z, Zhu T, Ye K, Xing Y, Sun C, Zhou $F$, et al. Estimation and projection about the standardized prevalence of osteoporosis in mainland China. Arch Osteoporos. 2019;15(1):2.

17. Riggs BL, Melton lii LJ. The worldwide problem of osteoporosis: Insights afforded by epidemiology. Bone. 1995;17(5 SUPPL. 1):S505-11.

18. Cauley JA. Public health impact of osteoporosis. J Gerontol Ser A Biomed Sci Med Sci. 2013;68(10):1243-51.

19. Marks R, Allegrante JP, MacKenzie CR, Lane JM. Hip fractures among the elderly: causes, consequences and control. Ageing Res Rev. 2003;2(1):57-93.

20. Klibanski A, Adams-Campbell L, Bassford TL, Blair SN, Boden SD, Dickersin K, Gifford DR, Glasse L, Goldring SR, Hruska K. Osteoporosis prevention, diagnosis, and therapy. J Am Med Assoc. 2001;285(6):785-95.

21. Irani AD, Poorolajal J, Khalilian A, Esmailnasab N, Cheraghi Z. Prevalence of osteoporosis in Iran: a meta-analysis. J Res Med Sci. 2013;18(9):759-66.

22. Johnston CB, Dagar M. Osteoporosis in older adults. Med Clin North Am. 2020;104(5):873-84

23. Kanis JA, Delmas P, Burckhardt P, Cooper C, Torgerson D. Guidelines for diagnosis and management of osteoporosis. Osteoporos Int. 1997;7(4):390-406.

24. Ferrari R: Prevalence of osteoporosis in men aged $65-75$ in a primary care setting. A practice audit after application of the Canadian 2010 guidelines for osteoporosis screening. Clin Rheumatol. 2015, 34(3):523-527.

25. Modagan, Silambanan S, Menon PG, Arunalatha P: Comparison of bone mineral density with biochemical parameters and prevalence of osteopenia and osteoporosis in South Indian population. Biomed Pharmacol J. 2018;11(4):2209-2214.

26. Moher D, Shamseer L, Clarke M, Ghersi D, Liberati A, Petticrew M, Shekelle $P$, Stewart LA. Preferred reporting items for systematic review and metaanalysis protocols (PRISMA-P) 2015 statement. Syst Rev. 2015;4(1):1.

27. Morgan RL, Whaley P, Thayer KA, Schünemann HJ. Identifying the PECO: a framework for formulating good questions to explore the association of environmental and other exposures with health outcomes. Environ Int. 2018;121(Pt 1):1027.

28. Asadi Noghabi A, Alhani F, Peyrovi H. The concept of health in elderly people: a literature review. IJN. 2012;25(78):62-71.

29. Von Elm E, Altman DG, Egger M, Pocock SJ, Gøtzsche PC, Vandenbroucke $J P$, Initiative S. The Strengthening the Reporting of Observational Studies in Epidemiology (STROBE) statement: guidelines for reporting observational studies. Int J Surg. 2014;12(12):1495-9.

30. Mohamed Adel B, Hammad KB, Habil KM. Bone mineral density in healthy Syrian women measured by dual energy $X$-ray absorptiometry. Anthropol Rev. 2018;81(1):18-28.

31. Lau EM, Chung HL, Ha PC, Tang H, Lam D. Bone mineral density, anthropometric indices, and the prevalence of osteoporosis in Northern (Beijing) Chinese and Southern (Hong Kong) Chinese Women-The Largest Comparative Study to Date. J Clin Densitom Off J Int Soc Clin Densitom. 2015;18(4):519-24.

32. Silva ACV, da Rosa MI, Fernandes B, Lumertz S, Diniz RM, dos Reis Damiani MEF. Factors associated with osteopenia and osteoporosis in women undergoing bone mineral density test. Rev Bras Reumatol (English Ed). 2015;55(3):223-8
33. Kruavit A, Chailurkit L-O, Thakkinstian A, Sriphrapradang C, Rajatanavin $R$ : Prevalence of vitamin D insufficiency and low bone mineral density in elderly Thai nursing home residents. BMC Geriatr. 2012; 12.

34. Nobakht Motlagh F, Khani Jihoni A, Haidar Nia A, Kave M, Hajizadeh E, Babaee Haidar Abadi A, Hemati R. Prevalence of osteoporosis and its related factors in women referred to Fasa's Densitometry Center. Ilam Univ Med Sci. 2013;21(4):150-158.

35. Mautalen C, Schianchi A, Sigal D, Gianetti G, Vidan V, Bagur A, González D, Mastaglia S, Oliveri B. Prevalence of osteoporosis in women in Buenos Aires based on bone mineral density at the Lumbar Spine and Femur. J Clin Densitom. 2016;19(4):471-6.

36. Asaoka D, Nagahara A, Shimada Y, Matsumoto K, Ueyama H, Matsumoto K, Nakagawa Y, Takeda T, Tanaka I, Sasaki H, et al. Risk factors for osteoporosis in Japan: is it associated with Helicobacter pylori? Ther Clin Risk Manag. 2015;11:381-91

37. Lee DH, Youn HJ, Yi JE, Chin JY, Kim TS, Jung HO, Chang K, Choi YS, Jung JI. Gender difference in bone loss and vascular calcification associated with age. Korean Circ J. 2013;43(7):453-61.

38. Alibasic E, Ramic E, Mujanovic OB, Avdibasic E, Husic D, Alic A. Assessment of osteoporosis in family medicine obtained by ultrasound densitometry. Acta Inform Med. 2013;21(4):274-6.

39. Park EJ, Joo IW, Jang MJ, Kim YT, Oh K, Oh HJ. Prevalence of osteoporosis in the Korean population based on Korea National Health and Nutrition Examination Survey (KNHANES), 2008-2011. Yonsei Med J. 2014;55(4):1049-57.

40. Bhat KA, Kakaji M, Awasthi A, Shukla M, Dubey M, Srivastava R, Singh U, Gupta SK. High prevalence of osteoporosis and morphometric vertebral fractures in indian males aged 60 years and above: should age for screening be lowered? J Clin Densitom Off J Int Soc Clin Densitom. 2018;21(4):517-23.

41. Kok-Yong C, Alia Annessa Ain K, Nie Yen L, Ima-Nirwana S. Effects of age, sex, and ethnicity on bone health status of the elderly in Kuala Lumpur, Malaysia. Clin Intervent Aging. 2016;11:767-73.

42. Kim KH, Lee K, Ko Y-J, Kim SJ, Oh SI, Durrance DY, Yoo D, Park SM. Prevalence, awareness, and treatment of osteoporosis among Korean women: the Fourth Korea National Health and Nutrition Examination Survey. Bone. 2012;50(5):1039-47.

43. Lee KS, Bae SH, Lee SH, Lee J, Lee DR. New reference data on bone mineral density and the prevalence of osteoporosis in Korean adults aged 50 years or older: the Korea National Health and Nutrition Examination Survey 2008-2010. J Korean Med Sci. 2014;29(11):1514-22.

44. Tian L, Yang R, Wei L, Liu J, Yang Y, Shao F, Ma W, Li T, Wang Y, Guo T: Prevalence of osteoporosis and related lifestyle and metabolic factors of postmenopausal women and elderly men: A cross-sectional study in Gansu province, Northwestern of China. Medicine. 2017;96(43):e8294.

45. Maddah M, Sharami SH, Karandish M. Educational difference in the prevalence of osteoporosis in postmenopausal women: a study in northern Iran. BMC Public Health. 2011;11:845.

46. Puth MT, Klaschik M, Schmid M, Weckbecker K, Münster E. Prevalence and comorbidity of osteoporosis-a cross-sectional analysis on 10,660 adults aged 50 years and older in Germany. BMC Musculoskelet Disord. 2018;19(1):144

47. Agrawal NK, Sharma B. Prevalence of osteoporosis in otherwise healthy Indian males aged 50 years and above. Arch Osteoporos. 2013;8(1-2):116.

48. Bucciarelli P, Martini G, Martinelli I, Ceccarelli E, Gennari L, Bader R, Valenti R, Franci B, Nuti R, Mannucci PM. The relationship between plasma homocysteine levels and bone mineral density in post-menopausal women. Eur J Intern Med. 2010;21 (4):301-5.

49. Po-Han C, Lin M-S, Tung-Jung H, Mei-Yen C: Prevalence of and factors associated with adopting bone health promoting behaviours among people with osteoporosis in Taiwan: a cross-sectional study. BMJ Open. 2017;7(9).

50. Gupta R, Al-saeed O, Azizieh F, Albusairi A, Gupta P, Mohammed A. Evaluation of bone mineral density in postmenopausal women in Kuwait. J Clin Densitom. 2012;15(2):211-6.

51. Cui R, Zhou L, Li Z, Li Q, Qi Z, Zhang J. Assessment risk of osteoporosis in Chinese people: relationship among body mass index, serum lipid profiles, blood glucose, and bone mineral density. Clin Interv Aging. 2016;11:887-95.

52. Noel SE, Mangano KM, Griffith JL, Wright NC, Dawson-Hughes B, Tucker $\mathrm{KL}$. Prevalence of osteoporosis and low bone mass among puerto 
rican older adults. J Bone Miner Res Off J Am Soc Bone Miner Res. 2018;33(3):396-403.

53. Shetty S, Kapoor N, Naik D, Hesarghatta SA, Prabu S, Thomas N, Mandalam Subramaniam S, Thomas Vizhalil P. Osteoporosis in healthy South Indian males and the influence of life style factors and vitamin D status on bone mineral density. J Osteoporos. 2014;2014:5.

54. Lekamwasam S, Wijayaratne L, Rodrigo M, Hewage U. Prevalence and determinants of osteoporosis among men aged 50 years or more in Sri Lanka: a community-based cross-sectional study. Arch Osteoporos. 2009;4(1-2):79-84.

55. Cheng XG, Yang DZ, Zhou Q, Zhuo TJ, Zhang HC, Xiang J, Wang HF, Ou PZ, Liu JL, Xu L, et al. Age-related bone mineral density, bone loss rate, prevalence of osteoporosis, and reference database of women at multiple centers in China. J Clin Densitom. 2007;10(3):276-84.

56. Yin-Fan C, Chin-Sung C, Mei-Wen W, Chun-Feng W, Chuan-Yu C, Chang $\mathrm{H}-\mathrm{J}, \mathrm{Kuo} \mathrm{P}-\mathrm{H}, \mathrm{Wu} \mathrm{C}-\mathrm{H}$ : Effects of age and body mass index on thoracolumbar spine $x$-ray for diagnosing osteoporosis in elderly women: Tianliao Old People (TOP) Study 07. PLoS ONE. 2016;11(9).

57. Ma Y, Fu L, Jia L, Han P, Kang L, Yu H, Chen X, Yu X, Hou L, Wang L, et al. Muscle strength rather than muscle mass is associated with osteoporosis in older Chinese adults. J Formos Med Assoc. 2018;117(2):101-8.

58. Choi YJ, Oh HJ, Kim DJ, Lee Y, Chung YS. The prevalence of osteoporosis in Korean adults aged 50 years or older and the higher diagnosis rates in women who were beneficiaries of a national screening program: the Korea National Health and Nutrition Examination Survey 2008-2009. J Bone Miner Res Off J Am Soc Bone Miner Res. 2012;27(9):1879-86.

59. Pourhashem Z, Bayani M, Noreddini H, Bijani A, Hosseini SR. Prevalence of osteoporosis and its association with serum vitamin D level in older people in Amirkola, North of Iran. Caspian J Intern Med. 2012;3(1):347-53.

60. Sheng Z, Xu K, Ou Y, Dai R, Luo X, Liu S, Su X, Wu X, Xie H, Yuan L, et al. Relationship of body composition with prevalence of osteoporosis in central south Chinese postmenopausal women. Clin Endocrinol. 2011;74(3):319-24.

61. Lim Y, Jo K, Ha HS, Yim HW, Yoon KH, Lee WC, Son HY, Baek KH, Kang $\mathrm{MI}$. The prevalence of osteoporosis and the rate of bone loss in Korean adults: the Chungju metabolic disease cohort (CMC) study. Osteoporos Int. 2017;28(4):1453-9.

62. Chen P, Li Z, Hu Y. Prevalence of osteoporosis in China: a meta-analysis and systematic review. BMC Public Health. 2016;16(1):1039.

63. Zamani M, Zamani V, Heidari B, Parsian H, Esmaeilnejad-Ganji SM. Prevalence of osteoporosis with the World Health Organization diagnostic criteria in the Eastern Mediterranean Region: a systematic review and meta-analysis. Arch Osteoporos. 2018;13(1):129.

64. Smith R. Idiopathic juvenile osteoporosis: experience of twenty-one patients. Rheumatology. 1995;34(1):68-77.

65. Lin CC, Li Cl, Meng NH, Liu CS, Lin CH, Lin WY, Chang CK, Lee YD, LiTC. Osteoporosis: prevalence and risk factors among Taiwanese metropolitan elderly. Eur Geriatr Med. 2015;6(4):303-8.

66. Alswat KA. Gender disparities in osteoporosis. J Clin Med Res. 2017;9(5):382-7.

67. Khosla S, Riggs BL. Pathophysiology of age-related bone loss and osteoporosis. Endocrinol Metab Clin. 2005;34(4):1015-30.

68. Salari N, Ghasemi H, Mohammadi L, et al. The global prevalence of osteoporosis in the world: a comprehensive systematic review and meta-analysis. J Orthop Surg Res. 2021;16:609. https://doi.org/10.1186/ s13018-021-02772-0.

69. Odén A, McCloskey EV, Kanis JA, Harvey NC, Johansson H. Burden of high fracture probability worldwide: secular increases 2010-2040. Osteoporosis Int. 2015;26:2243-8.

70. European Prospective Osteoporosis Study G, Felsenberg D, Silman AJ, et al. Incidence of vertebral fracture in Europe: results from the European Prospective Osteoporosis Study (EPOS). J Bone Miner Res. 2002;17(4): $716-24$.

71. Charles A, Keenan A. Osteoporosis in older people. J Pharm Pract Res. 2021;51:265-74.

\section{Publisher's Note}

Springer Nature remains neutral with regard to jurisdictional claims in published maps and institutional affiliations.
Ready to submit your research? Choose BMC and benefit from:

- fast, convenient online submission

- thorough peer review by experienced researchers in your field

- rapid publication on acceptance

- support for research data, including large and complex data types

- gold Open Access which fosters wider collaboration and increased citations

- maximum visibility for your research: over $100 \mathrm{M}$ website views per year

At BMC, research is always in progress.

Learn more biomedcentral.com/submissions 